\title{
ОЦІНЮВАННЯ ЕФЕКТИВНОСТІ ПІЛЬГ З ПОДАТКУ НА ДОХОДИ ФІЗИЧНИХ ОСІБ В КРАЇНАХ ЄС
}

\begin{abstract}
Анотація. Досліджено підходи до оцінювання пільг з податку на доходи фізичних осіб у західній фінансовій науці та проблемні аспекти їх застосування. Акцентовано увагу на виявленні основних причин неефективності національних систем пільг з податку на доходи фрізичних осіб в теоретичній літературі, а також визначенні їі наслідків. Відзначено, що оптимізація наявного переліку пільг з податку на доходи фізичних осіб має полягати в забезпеченні більшої їх спрямованості на підтримку найменш забезпечених та найбільш соціально вразливих верств населення. Зроблено висновок, що перерозподільні наслідки застосовуваних податкових пільг значною мірою залежать від особливостей національної системи податку на доходи фізичних осіб (шкали податкових ставок, визначеної одиниці оподаткування тощо), а також характеристик тих груп населення, на які зазначені пільги спрямовані, натомість в меншому ступені визначаються конструкцією використовуваного інструменту (пільги).
\end{abstract}

Ключові слова: податок на доходи фізичних осіб, податкова пільга, ефективність, перерозподіл, податкова знижка, податковий кредит.

Rainova Larysa

SESE «The Academy of Financial Management»

\section{EVALUATION OF THE EFFECTIVENESS OF PERSONAL INCOME TAX BENEFITS IN EU COUNTRIES}

Summary. Approaches to the assessment of personal income tax benefits in Western financial science and the consequences of their application are investigated. In this context, it is noted that methods of estimating budget losses from the provision of tax benefits, rather than assessing the effectiveness of their application, in particular, in relation to the initial objectives of their provision, are most often used. For the implementation of the latter, model calculations (microsimulation models, distributional modeling, etc.) are usually applied. However, exactly the combination of these two estimates allows ordering the system of tax benefits to increase the mobilization of domestic revenues. It is determined that taking into account the purpose of providing personal income tax benefits, the assessment of their effectiveness and efficiency should be carried out in the context of achieving redistributive goals - reducing income inequality and increasing social justice. It is established that the inefficiency of personal income tax benefits in the theoretical literature is primarily due to the fact that the incentives provided to them largely extend also to groups of the population who need it the least, and therefore greater benefits in the form of reducing tax liability for a relatively wide range of tax expenses (deductions for the acquisition of real estate, including on a mortgage, tax benefits on expenses for charity, pensions, health care, education, etc.) are received by taxpayers with higher incomes. This aspect, in particular, was also the basis for development of researches about the so-called «hidden welfare state». It is noted that at application of a progressive scale of personal income taxation, this leads to a decrease in the degree of progression, while on a proportional scale - to its actual regression. It is proved that the optimization of the existing list of benefits on a personal income tax should be to ensure their greater focus on supporting the poorest and socially vulnerable segments of the population. The conclusion is confirmed that the redistributive consequences of the applied tax benefits largely depend on the peculiarities of the national personal income tax system (scale of tax rates, defined unit of taxation, etc.), as well as the characteristics of those groups of the population to which these benefits are directed, but less determined by a design of the used tool (tax benefit).

Keywords: personal income tax, tax benefits, effectiveness, redistribution, tax allowance, tax credit.

$\Pi$ остановка проблеми. Пільги з податку на доходи фізичних осіб е одніею з найвагоміших, хоча й неявних, статей бюджетних витрат в багатьох країнах, як з числа розвинених, так і тих, що розвиваються [1]. Натомість зберігається тенденщія щодо подальшого поширення їх застосування з метою досягнення різноманітних завдань: перерозподілу доходів на користь малозабезпечених громадян, заохочення зайнятості й самозайнятості населення, створення нових робочих місць, стимулювання розвитку недержавного пенсійного забезпечення, державної підтримки в придбанні житла, отриманні освіти й професійної підготовки, медичних послуг та ін. Досить швидкою динамікою в останні роки характеризуються, зокрема, соціальні податкові витрати, метою яких є за- безпечення соціальної підтримки населення [2]. 3 огляду на зазначене, своєчасна належна оцінка результативності та ефективності використовуваної системи пільг е важливою в контексті запобігання в подальшому їх надмірному використанню, а також для забезпечення контролю за відповідністю зазначених пільг тим цілям, які ставились напередодні їх введення.

Аналіз останніх досліджень і публікацій. Грунтовних досліджень, присвячених вивченню та оцінці перерозподільних наслідків застосування пільг з податку на доходи фрізичних осіб натомість не так вже й багато. Зокрема, можна відмітити праці С. Аврам, С. Баріос, А. Вагстаф, Г. Вербіст, Е. Дослаер, Л. Гандуліа, Ф. Фігарі [3-6]. Певним поясненням зазначеного може бути відсутність консенсусу щодо 
стандартизованого способу вимірювання податкових витрат, а також труднощі із здійсненням їх порівнянь між країнами через неповноту наявних даних, 3 урахуванням чого доводиться вдаватись до різного роду припущень, необхідних як для обчислення податкових витрат, так і для вивчення наслідків їх надання, зокрема, див. Л. Берман [7]. Зазначені оцінки однак набувають все більшої актуальності. Висвітленню особливостей та проблемних аспектів системи пільг з податку на доходи фізичних осіб в Україні присвячено дослідження багатьох вітчизняних авторів, серед яких варто відмітити праці Ю.Б. Іванова, Ю.В. Сибірянської, А.М. Соколовської, О.М. Тимченко, В.Б. Тропіної, К.І. Швабія [8-11].

Виділення невирішених раніше частин загальної проблеми. Питання аналізу однієї 3 найбільш значних статей бюджетних втрат, пов'язаних із наданням пільг 3 податку на доходи фізичних осіб, залишається актуальним 3 огляду на підвищену увагу багатьох країн до оцінки обсягів таких втрат та потреби в ініціюванні відповідних корекцій, що й обумовлюе потребу у проведенні подальших досліджень в зазначеному напрямі.

Цілі статті. Дослідити підходи до оцінювання пільг з податку на доходи фізичних осіб у західній фрінансовій науці; виявити проблемні аспекти, пов'язані із врахуванням, неконтрольованим поширенням, а також аналізом ефективності застосування зазначених пільг; визначити основні чинники, які обумовлюють їх перерозподільний вплив.

Виклад основного матеріалу дослідження. Зважаючи на мету надання пільг 3 податку на доходи фізичних осіб оцінювання ї результативності та едективності має здійснюватись у контексті досягнення перерозподільних цілей - зменшення нерівності доходів й підвищення соціальної справедливості. Втім, саме зазначені пільги часто зазнають критики як непрозорі, неефективні та несправедливі, оскільки значно менше контролюються порівняно $з$ програмами соціальних трансфертів 3 аналогічними цілями; вони набагато рідше підлягають реформуванню або скасуванню навіть у періоди рецесії чи уповільнення економічного зростання, можуть створювати небажані побічні ефекти, а їх зростання з часом може бути набагато складніше враховувати чи обмежувати [12].

Неедективність пільг 3 податку на доходи фрізичних осіб найчастіше аргументується тим, що згенеровані ними стимули переважно спрямовані на групи населення, які найменше їх потребують. Саме вони отримують непропорційно велику частку ресурсів, розподілених за допомогою пільг з податку на доходи фрізичних осіб, а відтак і найбільшу вигоду від такого типу політики (Л. Берман, М. Фауп [13], К. Кавальканті, Ч. Лі [14]). За умови застосування прогресивної шкали оподаткування доходів орізичних осіб це призводить до зниження ступеня прогресії, тоді як за пропорційної шкали - до фрактичної регресивності податку. Хоча наведені висновки значною мірою базуються на дослідженнях податку на доходи фрізичних осіб у США, в меж- ax яких значного поширення набули численні вирахування різного роду витрат, див., наприклад, М. Шайлер [15], тим не менше, такі висновки зустрічаються і в роботах, присвячених аналізу положень податкового законодавства інших країн, зокрема, щодо окремих категорій витрат, наприклад, із сплати процентів за іпотечним кредитом, на охорону здоров'я тощо (праці Р. Яходи, Я. Годарової [16]; С. Пеллегріно, М. Пьяченца, Ж. Туратті [17], Бранко і Коста [18]). Менше відомо про перерозподільні ефректи податкових витрат, фрункціонально еквівалентних грошовій допомозі.

Важливим напрямом досліджень, серед яких праці А. Вагстафрд, Е. Дорслаер та ін. [5; 19], Г. Вербіст, Ф. Фігарі [6;20], стали порівняння різних видів податкових витрат для обраного переліку країн з метою вивчення забезпечуваного ними ступеня прогресії в оподаткуванні, Зокрема виявлено, що перерозподільні едекти різних видів пільг з податку на доходи фpiзичних осіб є різними. Податкові кредити, як правило, сприяють прогресії. Проте не завжди вони $є$ едрективними в контексті спрямування ресурсів до домогосподарств у нижній частині розподілу доходів. Винятками є відшкодовувані податкові кредити, орієнтовані на домогосподарства з низьким рівнем доходу. Виявлено, що зазначені податкові кредити є досить прогресивними майже незалежно від умов, у яких вони діють [13]. Податкові вирахування (які залежать від доходу) зазвичай регресивні, тоді як податкові знижки (фіксовані суми) є прогресивними. Широке застосування податкових кредитів, нестандартних вирахувань, а також звільнень має суттєвий вплив на рівень платоспроможності платників, що їх використовують, втім, це посилює горизонтальну нерівність.

Незважаючи на те, що вищезазначені дослідження місять цікаву інформацію щодо розподільних наслідків податкових пільг, їм притаманна низка недоліків. По-перше, оскільки податкові декларації не включають інформацію про платників податків, в яких відсутні обов'язки із сплати податку, дослідження, проведені на базі їх даних, фрактично не враховують доволі значну частину розподілу доходів. Більше того, прогресивність та перерозподільні наслідки застосовуваних пільг розраховуються щодо оподатковуваного, а не наявного доходу домогосподарств, таким чином, не враховуються будь-які ефректи взаємодії або компенсації, обумовлені впливом інших елементів системи податку на доходи фрізичних осіб, а також трансорертів (наприклад, багато грошових трансфертів не оподатковуються, втім $є$ важливою складовою отримуваних домогосподарствами доходів); неврахування зазначеного потенційно може призвести до невірних результатів. Подруге, методи декомпозиції, використані в цих дослідженнях, повинні передбачати, що зміна одного елемента системи податку на доходи фізичних осіб залишає без змін всі інші, а також права на отримання державної допомоги. Проте, зміна однієї статті податкових витрат може вплинути на право на отримання інших податкових пільг (knock-on effects), a, отже, на остаточне податкове зобов'язання. Крім того, 
зміни в податкових зобов'язаннях, у свою чергу, можуть вплинути на розмір державної допомоги. По-трете, ці дослідження не дають відповіді на питання, збільшиться чи зменшиться нерівність доходів за умови скасування окремих пільг. Нарешті, за низкою винятків, у цих дослідженнях не вдалося детально вивчити питання вибору дизайну пільг, а також виявити, чи матиме його зміна будь-які перерозподільні наслідки.

Щодо підходів до оцінки едективності податкових витрат (пільг), в окремих працях $[21$, с. 110] відзначається, що найчастіше розглядаються методики оцінки втрат бюджету від надання податкових пільг, а не оцінки ефективності їх застосування, зокрема, й відносно початкових цілей їх надання. Для здійснення останньої, зазвичай, застосовуються модельні розрахунки (мікроімітаційні моделі, дистрибутивне моделювання та ін.) [12]. Втім, саме поєднання цих двох оцінок дозволяе впорядкувати систему податкових пільг задля збільшення мобілізації внутрішніх доходів [22, с. 9].

В одній 3 небагатьох робіт, присвячених комплексній оцінці ефективності пільг 3 податку на доходи фрізичних осіб, зокрема, в дослідженнях С. Аврам [3; 23], для обчислення розміру та визначення розподільних наслідків податкових пільг використано EUROMOD мікроімітаційну модель податкових пільг, що Iрунтуеться на нормах податкового законодавства країн ЄC, а також мікроданих з обстеження домогосподарств згідно наявної статистики доходів і умов життя EU-SILC (European Union Statistics on Income and Living Conditions). Bapто відмітити, що вищезазначені дані $є$ також базою для здійснення модельних розрахунків і в низці інших досліджень, присвячених оцінці ефрективності застосування пільг з податку на доходи фізичних осіб у країнах ЄС. Зокрема, використання EUROMOD надає можливість забезпечувати моделювання минулих, поточних, майбутніх й альтернативних політичних заходів; проводити комплексну оцінку окремих таких заходів; виконувати моделювання сценарію редорми однієї країни стосовно іншої країни; здійснювати аналіз розподільних і бюджетних едректів. Втім, при інтерпретації результатів відмічаеться, що вони стосуються не фрактичного, а більше теоретичного ефекту розподілу податкових пільг.

Для більш детального дослідження питання щодо того, які різновиди пільг мають найбільший потенціал для перерозподілу в нижній його частині, а які, ймовірно, будуть спрямовані переважно на користь домогосподарств, що знаходяться у верхній частині розподілу доходів, головний акцент в низці праць зроблено лише на двох видах пільг - податкових знижках та податкових кредитах. Таким чином, 3 аналізу виключено такі інструменти, як доходи, звільнені від оподаткування, спеціальні ставки для деяких категорій платників податків або спеціальні ставки, що застосовуються до деяких видів доходів, а також норми, що стосуються вибору одиниці оподаткування. Звичайно, можна зауважити, як пояснюють автори досліджень, що через виключення зазначених інструментів аналіз є неповним, оскільки можна намагатись досягнути подібних цілей через одночасне використання різних інструментів. Втім, зосередження уваги на зазначених двох типах інструментів є важливим в тому сенсі, що дозволяе вийти за рамки простої кількісної оцінки упущених надходжень для того, щоб точніше вивчити, які особливості податкових знижок та податкових кредитів можуть забезпечити їх більшу прогресивність, а також яким чином вони залежать від більш широкого дизайну системи податку на доходи фізичних осіб в цілому.

В роботах представлено оцінки загального розміру податкових витрат, пов'язаних із наданням податкових знижок та податкових кредитів, а також їх оцінки в розрізі поділу на категорії - універсальні та цільові податкові знижки. Також показано, як вигоди від застосування двох видів податкових пільг змінюються залежно від розподілу доходу. Оцінку того, наскільки податкові знижки та податкові кредити сприяють посиленню або зменшенню нерівності, надано за результатами обчислення індексів перерозподілу (індекс Рейнольдса-Смоленського) та прогресивності (індекс Каквані). Для повноти даних додатково проведено обчислення середніх податкових ставок (ATR), а також коедіцієнтів концентрації щодо податкових знижок та податкових кредитів.

Перший загальний результат міжкраїнних порівнянь ефективності пільг з податку на доходи фрізичних осіб засвідчив, що податкові пільги, надані у формі податкових знижок та податкових кредитів, $є$ значною статтею витрат у порівнянні із державними надходженнями в більшості досліджуваних країн, хоча й існують значні міжнаціональні відмінності. Більше того, за окремими винятками, вони можуть охоплювати широкі верстви населення. Принаймні в дослідженому авторами переліку країн, вони ні в якому разі не були інструментами, призначеним лише або переважно для осіб з високими доходами. Втім, незважаючи на значне поширення, їх наслідки в частині розподілу не обов'язково були вагомими. Натомість підтвердились окремі висновки з літературних джерел про «приховану державу соціального добробуту» (hidden welfare state), згідно 3 якими податкові витрати значною мірою є вигіднішими для груп із середніми та високими доходами.

Інший загальний результат, який випливає 3 аналізу досліджених літературних джерел, свідчить про те, що розподільні наслідки пільг з податку на доходи фізичних осіб є складними та часто непередбачуваними. Зокрема, зазначені пільги можуть взаємодіяти між собою, а також із ширшою системою податків і трансфертів в цілому. Таким чином, їх редрормування для досягнення цілей перерозподілу може виявитися особливо проблематичним, навіть за умови абстрагування від будь-яких поведінкових едектів.

Хоча податкові пільги можуть мати схожі цілі 3 деякими програмами грошових трансфертів (наприклад, підтримка сімей 3 дітыми або покриття витрат на житло), наслідки використання зазначених інструментів (пільги 
і трансорерти) для цілей розподілу часто $є$ різними. Більше того, оскільки вони (пільги) діють в більш складний спосіб, ніж прямі грошові трансферти, їх набагато важче використовувати для досягнення певного результату розподілу. В наявній літературі 3 фріскальної соціології, значна частина якої присвячена сощіологічному аналізу оподаткування й державних фрінансів, зокрема, в роботах І.У. Мартін, М. Прасад [24]; Ш. Гангоф [25]; М. Прасад, І. Денг [26], йдеться про те, що деякі країни використовують податкову систему як альтернативу прямим соціальним витратам для забезпечення перерозподілу доходів. У роботі Л. Бермана й М. Фаупа показано, що навіть в цьому випадку результати розподілу навряд чи будуть аналогічними [13, с. 105]. Принаймні там, де йдеться про пільги 3 податку на доходи фізичних осіб, насамперед у вигляді знижок та кредитів, бенефіціари, як правило, можуть виявитись, як зазначалося вище, і в групах населення з середніми і високими доходами.

Перерозподільні наслідки податкових пільг суттево залежать від інших особливостей національної системи податку на доходи фрізичних осіб (таких, зокрема, як шкала податкових ставок або визначення одиниці оподаткування) та характеристик населення, на яке ці пільги спрямовані, втім, значно меншою мірою вони визначаються дизайном використовуваного інструменту (пільги). Подібні інструменти можуть мати дуже різні наслідки в контексті досягнення цілей перерозподілу, оскільки залежать від особливостей системи оподаткування доходів фізичних осіб, в межах якої вони діють. 3 другого боку, незважаючи на те, що використовувані пільги в межах одніеї категорії можуть бути дуже схожими за дизайном, їх перерозподільний вплив сильно відрізнятиметься при здійснені порівнянь між країнами. Таким чином, за вкрай незначними винятками (наприклад, відшкодовувані податкові кредити із перевіркою нужденності), дизайн інструменту (пільги) сам по собі містить мало інформації про ймовірний вплив на перерозподіл.

Загалом, при інтерпретації результатів досліджень слід враховувати низку застережень. По-перше, проблематичним при здійсненні насамперед міжкраїнних порівнянь залишаеться одночасне моделювання для цілей здійснення аналізу всіх передбачених законодавством пільг з податку на доходи фрізичних осіб з причини відсутності необхідних повних даних. Оцінки сукупного перерозподільного ефректу наданих пільг внаслідок зазначеного можуть виявитись не повністю співставними. Натомість, порівняння податкових інструментів (пільг) у межах окремих обраних категорій дозволяе певною мірою забезпечити вирішення зазначеної проблеми, зокрема, вказаний підхід було обрано в низці останніх робіт з зазначеної проблематики [4; 27]. По-друге, в роботах використовуються змодельовані розрахунки. Як результат, одержані висновки зазвичай відображають передбачуваний розрахований, а не фрактичний вплив податкових пільг. Нарешті, при здійсненні обчислень зазвичай не враховуеться жодних поведінкових адаптацій при скасуванні пільг, тобто зазвичай проводиться статичний аналіз наслідків їх застосування.

Отже, пільги 3 податку на доходи фрізичних осіб залишаються каналом, через який розподіляються значні ресурси, втім, наслідки їх фрункціонування $є$ досить неоднозначними; притаманні їм і помітні побічні едекти.

Висновки i пропозиції. Підсумовуючи, варто відмітити таке. В теоретичній літературі неефективність пільг з податку на доходи фрізичних осіб насамперед пов'язуеться 3 тим, що забезпечені ними стимули значною мірою розповсюджуються на групи населення, які найменше того потребують, внаслідок чого більші вигоди від зниження податкових зобов'язань щодо відносно широкого переліку пільг отримують платники податків 3 вищими доходами. Вказаний аспект, зокрема, і виявився підставою для розвитку досліджень про так звану «приховану державу соціального добробуту». Зауважено також, що наслідком зазначеного є зниження ступеню прогресії при застосуванні прогресивної шкали оподаткування доходів фрізичних осіб, тоді як за пропорційної шкали таке оподаткування фактично перетворюється на регресивне. Оптимізація наявного переліку пільг 3 податку на доходи фізичних осіб тому має полягати в забезпеченні більшої їх спрямованості на підтримку найменш забезпечених та соціально вразливих верств населення.

Перерозподільні наслідки застосовуваних податкових пільг значною мірою залежатимуть від особливостей національної системи податку на доходи фізичних осіб (шкали податкових ставок, визначеної одиниці оподаткування тощо), а також характеристик тих груп населення, на які пільги спрямовані, натомість в меншому ступені визначатимуться конструкцією зазначених пільг. Як наслідок схожі за побудовою інструменти можуть мати доволі різні наслідки в контексті досягнення цілей перерозподілу, оскільки, як відзначалося, переважно інші особливості системи податку на доходи фрізичних осіб та/або характеристики населення формуватимуть їх остаточний перерозподільний вплив.

При здійсненні міжкраїнних порівнянь проблематичним в першу чергу залишається одночасне моделювання для цілей здійснення аналізу всіх передбачених національним законодавством держави пільг 3 податку на доходи фізичних осіб через відсутність повних даних, внаслідок чого оцінки сукупного перерозподільного ефректу наданих пільг можуть виявитись не зовсім співставними. Натомість, забезпечити вирішення зазначеної проблеми певною мірою дозволяе порівняння податкових інструментів (пільг) у межах певних обраних їх категорій. Подібний підхід, зокрема, домінуе в низці останніх досліджень з зазначеної проблематики. Ще одним проблемним аспектом залишається те, що більшості робіт використовуються змодельовані розрахунки, в межах яких як правило не враховується жодних поведінкових адаптацій при зміні/скасуванні пільг з податку на доходи фрізичних осіб, тобто зазвичай проводиться статичний аналіз наслідків застосування зазначених пільг, яким не в повній мірі може бути врахований фрактичний їх вплив. 


\section{Список літератури:}

1. Tax Expenditures in OECD Countries. OECD Publishing. 2010. DOI: https://doi.org/10.1787/9789264076907-en

2. Morel N., Touzet C., Zemmour M. Fiscal Welfare and Welfare State Reform: A Research Agenda. LIEPP Working Paper. 2016. № 45. URL: https://core.ac.uk/download/pdf/35303565.pdf (дата звернення: 14.05.2021).

3. Avram S. Who benefits from the 'hidden welfare state'? The distributional effects of personal income tax expenditure in six countries. Journal of European Social Policy. 2018. Vol. 28. № 3. P. 271-293. DOI: https://doi.org/ $10.1177 / 0958928717735061$

4. Barrios S., Figari F., Gandullia L., Riscado S. The fiscal and equity impact of tax expenditures in the European Union. JRC Working Papers on Taxation and Structural Reforms. 2016. № 1. URL: https://ec.europa.eu/jrc/sites/ jrcsh/files/jrc104176.pdf (дата звернення: 11.05.2021).

5. Wagstaff A., van Doorslaer E. What Makes the Personal Income Tax Progressive? A Comparative Analysis of Fifteen OECD Countries. International Tax and Public Finance. 2001. Vol. 8. № 3. P. 299-316. DOI: https://doi.org/ 10.1023/A:1011268209860

6. Verbist G., Figari F. The redistributive effect and progressivity of taxes revisited: An International Comparison across the European Union. GINI Discussion Paper. 2013. № 88. URL: http://archive.uva-aias.net/uploaded_files/ publications/DP88-1.pdf (дата звернення: 11.05.2021).

7. Burman L.E. Is the Tax Expenditure Concept Still Relevant? National Tax Journal. 2003. Vol. 56. № 3. P. $613-627$. URL: https://www.ntanet.org/NTJ/56/3/ntj-v56n03p613-27-tax-expenditure-concept-still.pdf (дата звернення: 20.04.2021).

8. Иванов Ю.Б. Налогообложение доходов физических лищ: проблемы реформирования регулирующих механизмов социального характера. Налогообложение: проблемы науки и практики : монография. Харьков : ИД «ИНЖЭК», 2006. С. 157-175.

9. Податок на доходи фізичних осіб та єдиний соціальний внесок: новації реформ та їх наслідки : монографія. Київ : Алерта, 2018. 442 с.

10. Система податкових пільг в Україні у контексті европейського досвіду / Соколовська А.M., Єфименко T.I., Луніна І.О. та ін. Київ : НДФІ, 2006. 320 с.

11. Швабій К.I. Регулятивна ефрективність податку на доходи фрізичних осіб в Україні. Фінанси Украӥни. 2013. № 4. C. 27-44.

12. Tax Expenditures - Shedding Light on Government Spending through the Tax System. Lessons from Developed and Transition Economies / Ed. by H. Polackova Brixi, C.M. Valenduc, Z. Li Swift. The World Bank. 2004. URL: http://documents1.worldbank.org/curated/en/280461468325775264/pdf/275830PAPER0Tax0expenditures.pdf (дата звернення: 10.05.2021).

13. Burman L.E., Phaup M. Tax Expenditures, the Size and Efficiency of Government, and Implications for Budget Reform. Tax Policy and the Economy. 2012. Vol. 26. № 1. P. 93-124. DOI: https://doi.org/10.1086/665504

14. Cavalcanti C.B., Li Z. Reforming Tax Expenditure Programs in Poland. World Bank Policy Research Working Paper. 2000. № 2465. URL: https://openknowledge.worldbank.org/bitstream/handle/10986/19969/wps2465.pdf? sequence=1\&isAllowed=y (дата звернення: 10.05.2021).

15. Schuyler M. Baked in the Cake: Why the Progressivity of the Income Tax isn't Visible in the Distribution of Tax Expenditures. Tax Foundation Special Report. 2014. № 212. URL: https://taxfoundation.org/baked-cake-whyprogressivity-income-tax-isn-t-visible-distribution-tax-expenditures/ (дата звернення: 20.04.2021).

16. Jahoda R., Godarova J. Distribution Impact of the Mortgage Interest Deduction in the Czech Republic. Review of European Studies. 2014. Vol. 6. № 2. P 110-119. URL: http://www.ccsenet.org/journal/index.php/res/article/ view/35225 (дата звернення: 19.04.2021).

17. Pellegrino S., Piacenza M., Turati G. Assessing the Distributional Effects of Housing Taxation in Italy: From the Actual Tax code to Imputed Rent. CESifo Working Papers. 2011. № 3368. URL: https://www.cesifo.org/DocDL/ cesifo1_wp3368.pdf (дата звернення: 14.04.2021).

18. Branco R., da Costa E. Welfare State, Tax Expenditures and Inequality: Portugal in Comparative Perspective, 1989-2011. 2015. URL: https://www.academia.edu/12398221/Welfare_State_Tax_Expenditures_and_Inequality_ Portugal_in_comparative_perspective (дата звернення: 14.04.2021).

19. Wagstaff A., van Doorslaer, E., van der Burg H., Calonge S. ets. Redistributive Effect, Progressivity and Differential Tax Treatment: Personal Income Taxes in Twelve OECD Countries. Journal of Public Economics. 1999. Vol. 72. № 1. P. 73-98. DOI: https://doi.org/10.1016/S0047-2727(98)00085-1

20. Verbist G., Figari F. What Makes Personal Income Taxes Progressive? A Decomposition Across European Countries Using EUROMOD. Paper prepared for the IARIW $33^{\text {rd }}$ General Conference. Rotterdam, the Netherlands, August 24-30, 2014. URL: http://old.iariw.org/papers/2014/VerbistPaper.pdf (дата звернення: 11.04.2021).

21. Adema W., Fron P., Ladaique M. Is the European Welfare State Really More Expensive? Indicators on Social Spending, 1980-2012; and a Manual to the OECD Social Expenditure Database (SOCX). OECD Social, Employment and Migration Working Papers. 2011. № 124. DOI: https://doi.org/10.1787/5kg2d2d4pbf0-en

22. Laporte B., Caldeira E., de Quatrebarbes C., Bouterige Y. Tax Expenditure Assessment: From Principles to Practice. Methodological guide. Foundation for Studies and Research on International Development (Ferdi). 2018. URL: https://ferdi.fr/dl/df-PSDXZuxEEh8LihnEhHUoFkjx/tax-expenditure-assessment-from-principles-topractice-methodological-guide.pdf (дата звернення: 20.04.2021).

23. Avram S. The distributional effects of personal income tax expenditure. ISER Working Paper Series. 2014. № 2014-26. URL: https://www.econstor.eu/bitstream/10419/123806/1/791143104.pdf (дата звернення: 14.04.2021).

24. Martin I.W., Prasad M. Taxes and Fiscal Sociology. Annual Review of Sociology. 2014. Vol. 40. № 1. URL:https://escholarship.org/content/qt09x385sm/qt09x385sm_noSplash_86b258479f839850667810222d3b4c4f.pdf ?t=py6gop (дата звернення: 20.04.2021).

25. Ganghof S. Tax Mixes and the Size of the Welfare State: Causal Mechanisms and Policy Implications. Journal of European Social Policy. 2006. Vol. 16. № 4. P. 360-373. URL: https://citeseerx.ist.psu.edu/viewdoc/do wnload?doi=10.1.1.503.1160\&rep=rep1\&type=pdf (дата звернення: 03.05.2021).

26. Prasad M., Deng Y. Taxation and the Worlds of Welfare. LIS Working Paper Series. № 480. URL: http://www.lisdatacenter.org/wps/liswps/480.pdf (дата звернення: 04.05.2021).

27. Tax expenditures in direct taxation in EU Member States. European Commission. Occasional Papers. 2014. № 207. URL: https://ec.europa.eu/economy_finance/publications/occasional_paper/2014/pdf/ocp207_en.pdf (дата звернення: 26.04.2021). 


\section{References:}

1. OECD (2010) Tax Expenditures in OECD Countries. DOI: https://doi.org/10.1787/9789264076907-en

2. Morel N., Touzet C., Zemmour M. (2016) Fiscal Welfare and Welfare State Reform: A Research Agenda. LIEPP Working Paper, no. 45. Available at: https://core.ac.uk/download/pdf/35303565.pdf (accessed 14 May 2021).

3. Avram S. (2018) Who benefits from the 'hidden welfare state'? The distributional effects of personal income tax expenditure in six countries. Journal of European Social Policy, vol. 28, no. 3, pp. 271-293. DOI: https://doi.org/ $10.1177 / 0958928717735061$

4. Barrios S., Figari F., Gandullia L., Riscado S. (2016) The fiscal and equity impact of tax expenditures in the European Union. JRC Working Papers on Taxation and Structural Reforms, no. 1. Available at: https://ec.europa.eu/ jrc/sites/jrcsh/files/jrc104176.pdf (accessed 11 May 2021).

5. Wagstaff A., van Doorslaer E. (2001) What Makes the Personal Income Tax Progressive? A Comparative Analysis of Fifteen OECD Countries. International Tax and Public Finance, vol. 8, no. 3, pp. 299-316. DOI: https://doi.org/ 10.1023/A:1011268209860

6. Verbist G., Figari F. (2013) The redistributive effect and progressivity of taxes revisited: An International Comparison across the European Union. GINI Discussion Paper, no. 88. Available at: http://archive.uva-aias.net/ uploaded_files/publications/DP88-1.pdf (accessed 11 May 2021).

7. Burman L.E. (2003) Is the Tax Expenditure Concept Still Relevant? National Tax Journal, vol. 56, no. 3, pp. 613-627. Available at: https://www.ntanet.org/NTJ/56/3/ntj-v56n03p613-27-tax-expenditure-concept-still.pdf (accessed 20 April 2021).

8. Ivanov Yu.B. (2006) Nalogooblozheniye dokhodov fizicheskikh lits: problemy reformirovaniya reguliruyushchikh mekhanizmov sotsial'nogo kharaktera [Personal income taxation: problems of reforming regulatory mechanisms of social nature]. Nalogooblozheniye: problemy nauki i praktiki [Taxation: problems of science and practice]. Kharkiv: Publishing House «INZHEK». (in Russian)

9. (2018) Podatok na dokhody fizychnykh osib ta yedynyi sotsialnyi vnesok: novatsii reform ta yikh naslidky [Personal income tax and social security contributions: reform novations and their consequences]. Kyiv: Alerta. (in Ukrainian)

10. Sokolovska A.M. (2006) Cystema podatkovykh pilh v Ukraini u konteksti yevropeiskoho dosvidu [The system of tax benefits in Ukraine in the context of European experience]. Kyiv: NDFI.

11. Shvabii K.I. (2013) Rehuliatyvna efektyvnist podatku na dokhody fizychnykh osib v Ukraini [Regulatory efficiency of personal income tax in Ukraine]. Finance of Ukraine, no. 4, pp. 27-44.

12. Polackova Brixi H., Valenduc C.M., Swift Z.Li (2004) Tax Expenditures - Shedding Light on Government Spending through the Tax System. Lessons from Developed and Transition Economies. The World Bank. Available at: http://documents1. worldbank.org/curated/en/280461468325775264/pdf/275830PAPER0Tax0expenditures.pdf (accessed 10 May 2021).

13. Burman L.E., Phaup M. (2012) Tax Expenditures, the Size and Efficiency of Government, and Implications for Budget Reform. Tax Policy and the Economy, vol. 26, no. 1, pp. 93-124. DOI: https://doi.org/10.1086/665504

14. Cavalcanti C.B., Li Z. (2000) Reforming Tax Expenditure Programs in Poland. World Bank Policy Research Working Paper, no. 2465. Available at: https://openknowledge.worldbank.org/bitstream/handle/10986/19969/ wps2465.pdf? sequence=1\&isAllowed=y (accessed 10 May 2021).

15. Schuyler M. (2014) Baked in the Cake: Why the Progressivity of the Income Tax isn't Visible in the Distribution of Tax Expenditures. Tax Foundation Special Report, no. 212. Available at: https://taxfoundation.org/baked-cakewhy-progressivity-income-tax-isn-t-visible-distribution-tax-expenditures/ (accessed 20 April 2021).

16. Jahoda R., Godarova J. (2014) Distribution Impact of the Mortgage Interest Deduction in the Czech Republic. Review of European Studies, vol. 6, no. 2, pp. 110-119. Available at: http://www.ccsenet.org/journal/index.php/res/ article/view/35225 (accessed 19 April 2021).

17. Pellegrino S., Piacenza M., Turati G. (2011) Assessing the Distributional Effects of Housing Taxation in Italy: From the Actual Tax code to Imputed Rent. CESifo Working Papers, no. 3368. Available at: https://www.cesifo.org/ DocDL/cesifo1_wp3368.pdf (accessed 14 April 2021).

18. Branco R., da Costa E. (2015) Welfare State, Tax Expenditures and Inequality: Portugal in Comparative Perspective, 1989-2011. Available at: https://www.academia.edu/12398221/Welfare_State_Tax_Expenditures_ and_Inequality_Portugal_in comparative perspective (accessed 14 April 2021).

19. Wagstaff A., van Doorslaer, E., van der Burg H., Calonge S. ets. (1999) Redistributive Effect, Progressivity and Differential Tax Treatment: Personal Income Taxes in Twelve OECD Countries. Journal of Public Economics, vol. 72, no. 1, pp. 73-98. DOI: https://doi.org/10.1016/S0047-2727(98)00085-1

20. Verbist G., Figari F. (2014) What Makes Personal Income Taxes Progressive? A Decomposition Across European Countries Using EUROMOD. Proceedings of the IARIW $33^{\text {rd }}$ General Conference (the Netherlands, Rotterdam, August 24-30). Available at: http://old.iariw.org/papers/2014/VerbistPaper.pdf (accessed 11 April 2021).

21. Adema W., Fron P., Ladaique M. (2011) Is the European Welfare State Really More Expensive? Indicators on Social Spending, 1980-2012; and a Manual to the OECD Social Expenditure Database (SOCX). OECD Social, Employment and Migration Working Papers, no. 124. DOI: https://doi.org/10.1787/5kg2d2d4pbf0-en

22. Laporte B., Caldeira E., de Quatrebarbes C., Bouterige Y. (2018) Tax Expenditure Assessment: From Principles to Practice. Methodological guide. Foundation for Studies and Research on International Development (Ferdi). Available at: https:/ferdi.fr/dl/df-PSDXZuxEEh8LihnEhHUoFkjx/tax-expenditure-assessment-from-principlesto-practice-methodological-guide.pdf (accessed 20 April 2021).

23. Avram S. (2014) The distributional effects of personal income tax expenditure. ISER Working Paper Series, no. 2014-26. Available at: https://www.econstor.eu/bitstream/10419/123806/1/791143104.pdf (accessed 14 April 2021).

24. Martin I.W., Prasad M. (2014) Taxes and Fiscal Sociology. Annual Review of Sociology, vol. 40, no. 1. Available at: https://escholarship.org/content/qt09x385sm/qt09x385sm_noSplash_86b258479f839850667810222d3b4c4f.pdf ?t=py6gop (accessed 20 April 2021).

25. Ganghof S. (2006) Tax Mixes and the Size of the Welfare State: Causal Mechanisms and Policy Implications. Journal of European Social Policy, vol. 16, no. 4, pp. 360-373. Available at: https://citeseerx.ist.psu.edu/viewdoc/ download?doi=10.1.1.503.1160\&rep=rep1\&type=pdf (accessed 14 April 2021).

26. Prasad M., Deng Y. (2009) Taxation and the Worlds of Welfare. LIS Working Paper Series, no. 480. Available at: http://www.lisdatacenter.org/wps/liswps/480.pdf (accessed 04 May 2021).

27. European Commission (2014) Tax expenditures in direct taxation in EU Member States. Occasional Papers, no. 207. Available at: https://ec.europa.eu/economy_finance/publications/occasional_paper/2014/pdf/ocp207_en.pdf (accessed 26 April 2021). 